El imaginario colectivo sobre internet de los nativos digitales argentinos que ingresan a la universidad

Marcelo Norberto Botto y Marisol Méndez Spensieri

http://perio.unlp.edu.ar/ojs/index.php/question/article/view/4539

Cita sugerida: Botto, M., y Méndez Spensieri, M. (2018). El imaginario colectivo sobre internet de los nativos digitales argentinos que ingresan a la universidad. Question, 1(58), e046. doi:https://doi.org/10.24215/16696581e046

\title{
El imaginario colectivo sobre internet de los nativos digitales argentinos que ingresan a la universidad
}

\author{
The collective imaginary about internet of argentine digital natives \\ who start university
}

\author{
Marcelo Norberto Botto marcelobotto@yahoo.com.ar \\ http://orcid.org/0000-0003-3693-7068 \\ Universidad Argentina de la Empresa (Argentina)
}

Marisol Méndez Spensieri marisol.ms@hotmail.com

http://orcid.org/0000-0002-2193-8562

Universidad Argentina de la Empresa (Argentina)

\section{Resumen}

Internet es utilizada cotidianamente por los jóvenes nativos digitales con la naturalidad propia de aquellos que crecieron con las potencialidades que brinda esta tecnología. El vínculo establecido a partir de la interacción y el uso de las redes sociales, los juegos en red y los videos de Youtube deriva en una concepción particular de lo que es internet, que en muchos casos lleva a una idealización de sus alcances y posibilidades.

Esa idealización muchas veces impide que se interroguen sobre las características, funcionamiento o consecuencias de internet, debido a que comparten una percepción sobre las 
potencialidades y universalidad de esa tecnología, que forma parte de una construcción imaginaria colectiva que los caracteriza.

En el presente trabajo se realiza un primer abordaje acerca de los conocimientos específicos que sobre internet poseen jóvenes universitarios de la región del Área Metropolitana de Buenos Aires (AMBA) y particularmente, se trata de identificar las construcciones colectivas imaginarias que estos nativos digitales elaboran de la red de redes.

Palabras clave: Imaginario colectivo; nativos digitales; estudiantes universitarios; Internet; AMBA.

\section{Abstract}

Internet is used daily by young digital natives with the naturalness of those who grew up with the potential of this technology. The relationship established from the interaction and use of social networks, online games and Youtube videos derives from a particular conception of what the internet is, which in many cases leads to an idealization of its scope and possibilities.

This idealization often prevents them from being questioned about the characteristics, functioning or consequences of the internet, because they share a perception about the potential and universality of this technology, which is part of an imaginary collective construction that characterizes them.

In the present work, a first approach is made about the specific knowledge that young university students in the Metropolitan Area of Buenos Aires (AMBA) have about the internet and, in particular, it is about identifying the imaginary collective constructions that these digital natives elaborate from the network of networks.

Keywords: Imaginary collective; digital natives; university students; Internet; AMBA.

Muchos adolescentes y jóvenes nativos digitales de occidente utilizan de manera cotidiana las tecnologías potenciadas por internet con la naturalidad propia de los que crecieron teniendo a su alcance smarthphones, tablets, consolas de videojuegos y computadoras como parte del mobiliario del hogar.

La facilidad del uso de estos recursos para la satisfacción de variados tipos de necesidades llevó a la realización de estudios académicos que vieron a internet como un recurso de poder y 
que la vincularon con la construcción de nuevas formas de cultura y con la creación de imaginarios colectivos específicos. Además hay una amplia bibliografía que la analiza desde el impacto que provoca en la vida social e individual.

En este caso, el tema a abordar es menos tratado en el mundo académico ya que está relacionado con el conocimiento mismo que poseen los jóvenes digitalizados sobre internet y no con el impacto de su uso. Específicamente, se busca realizar un primer abordaje sobre el conocimiento que poseen los ingresantes a las universidades del Área Metropolitana de Buenos Aires (AMBA) sobre esta tecnología.

Para los nativos digitales argentinos que habitan en esta zona geográfica, el vínculo establecido a partir de la interacción y el uso de las redes sociales, los juegos en red y los videos de Youtube deriva en una concepción particular de lo que es internet, que en muchos casos lleva a una idealización de sus alcances y posibilidades. Es probable que los jóvenes del AMBA, que muchas veces tienen acceso permanente a la red, no indaguen respecto a las características, funcionamiento o consecuencias de internet, debido a que comparten una percepción sobre las potencialidades y universalidad de esa tecnología, que forma parte de una construcción imaginaria colectiva que los caracteriza.

La respuesta a lo planteado en el párrafo anterior requiere indagar a numerosos grupos de jóvenes y sectores adolescentes que integran el amplio colectivo de los nativos digitales, lo que demanda dar pasos sucesivos hasta obtener la suficiente cantidad de información para brindar una explicación generalizada que permita dar cuenta del imaginario construido por estos sectores sobre internet.

El primer paso que se pretendió dar con este estudio está vinculado a la manera en que los jóvenes que transitan el primer y segundo año de carreras universitarias vinculadas con el área de las Ciencias Sociales perciben a internet, con la clara intención de esbozar los elementos constitutivos de un imaginario colectivo propio de este grupo específico de nativos digitales.

Para ello se recurrió a un abordaje cuali-cuantitativo, cuyas técnicas metodológicas fueron principalmente la indagación bibliográfica, entrevistas con preguntas abiertas y en profundidad. Para la obtención de datos a partir de entrevistas con preguntas abiertas se interpelaron, entre mayo y noviembre de 2016, a 112 estudiantes de entre 19 y 26 años, de universidades privadas y públicas del Área Metropolitana de Buenos Aires (AMBA). Por otra parte, se efectuaron seis entrevistas en profundidad a alumnos de universidades estatales para obtener información más precisa sobre las percepciones que estos jóvenes poseen sobre variados aspectos de internet. 
El objetivo principal de este trabajo consistió en indagar acerca de los conocimientos específicos que sobre internet poseen jóvenes universitarios de la región del AMBA y particularmente, identificar las construcciones colectivas imaginarias que estos nativos digitales elaboran de la red de redes.

\section{Definición y características de internet}

Dada la complejidad que supone internet, tanto por sus características concretas como por el uso que las personas hacen de ella, las definiciones sobre qué es internet no son sencillas de alcanzar. El concepto puede ser abarcado desde diferentes aspectos que son parte de un todo: ¿es una tecnología, una herramienta, una red de dispositivos o un medio masivo de comunicación?

Si se lo conceptualiza como un medio masivo, no sería preciso utilizarlo de manera genérica, sino que debería ser re-articulado dependiendo la situación. Así lo plantea Merril Morris (1996), ya que al permitir la comunicación uno a uno, en grupos o abiertamente, internet es un medio masivo multifacético, es decir, contiene muchas configuraciones diferentes de la comunicación. El autor Ed Krol, quien introdujo la idea 'red de redes' (1992), explica que internet es un recurso que conecta millones de usuarios a través de redes que están basadas en protocolos fijados, lo que supone un método acordado entre partes para permitir una comunicación (como el TCP/IP). Pero internet también tiene entradas a redes y servicios que están basados en otros protocolos (como UNIX).

Para Castells (1999), internet es una "red de redes de ordenadores capaces de comunicarse entre ellos", por ende una tecnología. Pero va más allá al proponer que es también un medio de comunicación, de interacción y de organización social sobre la cual se basa un nuevo tipo de sociedad que denomina sociedad red. Los fenómenos económicos, políticos y culturales están integrados también en internet.

Además, refiriéndose a la red de redes como un medio, considera que produce una nueva forma de comunicación que es masiva e individual porque alcanza a un público global pero con "contenido autogenerado, de emisión autodirigida y de recepción autoselectiva" (Castells, 2008).

Internet, además, presenta una particular arquitectura que dificulta una visión de redes de intercambio horizontal, es decir de una multiplicidad horizontal. En tal sentido, el sociólogo Mariano Zukerfeld (2010) plantea que en realidad internet está conformada por diferentes 
niveles con determinadas características que llevan a pensarla como una estratificación vertical. Estos niveles los divide en cinco: red social, contenidos, software, hardware e infraestructura.

El concepto de que internet no es una red sino un conjunto de redes, al fin y al cabo, no le interesa mucho al usuario. Las personas utilizan internet con propósitos específicos, como acceder a sitios webs, descargar contenidos, entre otros usos. Los usuarios no se preguntan, tal como lo describe Krol (1992), por qué las personas hacen uso de algo que no saben bien qué es, cómo funciona ni por qué, en un mundo en el que internet está tan arraigada en las acciones diarias que se la utiliza casi de manera natural.

Sin embargo, internet es un conjunto de redes integradas por conexiones de comunicación y físicas que conforman una gigantesca estructura que, entre otras cosas, está formada por cables que se fueron cambiando a través de los años -en la actualidad se utilizan en su mayoría los cables de fibra óptica- según avanzaba la tecnología. Tal como explica Natalia Zuazo (2013), son 250 cables que unen casi un millón de kilómetros y que conectan los continentes atravesando los océanos, bajo el mar. El 95\% de las comunicaciones del mundo, y por lo tanto toda la información que las personas envían por internet, pasa a través de estas redes de fibra óptica terrestres y submarinas, que deben ser instaladas, mantenidas y cambiadas, de ser necesario.

Es por ello que existen compañías que son proveedoras del servicio de internet (en Argentina Speedy de Telefónica, Arnet de Telecom y Fibertel del Grupo Clarín) y compañías que son proveedoras del llamado backbone o columna vertebral de internet, que no son tan conocidas. Se clasifican en Tier 1, 2 y 3 según su presencia y alcance, ya sea global, regional o local. Del primer nivel existen en el mundo pocas empresas que son las dueñas de los cables: Level 3, AOL, AT\&T, Verizon Business, NTT Communications, Qwest, Cogent, Sprint, Deutsche Telekom, TeliaSonera y Telefonica Global Solutions. La mayoría de estas poseen capitales estadounidenses. A su vez existen organizaciones que realizan específicamente reparación e instalación de cables, en su mayoría hechas por Alcatel y Tyco.

Para asegurar que todas las redes funcionen bien, existen los NOC (Network Operations Center) que son centros de operaciones con equipos de monitoreo. Los datos que circulan a través de internet quedan guardados en equipos de almacenamiento llamados servidores, que se encuentran en los datacenters, muchas veces en el mismo edificio que el NOC. Estos pueden llegar a ser un piso o un edificio entero. 
Los 13 servidores raíz (o madre) son operados por 12 organizaciones independientes que utilizan la tecnología anycast y cada servidor tiene "instancias" en varios puntos del mundo a la vez. El resto está operado desde Estados Unidos.

Significa entonces que, si bien muchas veces no se piense en ello, internet supone un trabajo complejo que precisa de esfuerzo técnico y muchos especialistas. Además alrededor de la tecnología utilizada cotidianamente también hay un gran negocio.

Por lo tanto, internet es un sistema en el que intervienen diferentes actores y que está regulado por instituciones para garantizar su disponibilidad, accesibilidad, seguridad y estabilidad.

Por su parte, cada país a través de algún ministerio u organismo especializado establece los marcos legales y las políticas para el desarrollo y uso de las redes y sistemas de información. Existen además organismos supranacionales como la Unión Internacional de Telecomunicaciones, perteneciente a las Naciones Unidas, que regula y promueve usos y aplicaciones de internet.

La gestión de los nombres de dominios estuvo históricamente bajo el control del gobierno de Estados Unidos, pero desde octubre de 2016 es injerencia exclusiva de la ICANN, una organización independiente y sin ánimos de lucro que opera a nivel internacional, según lo publicado por la Revista Fibra (2016).

Los factores descriptos anteriormente forman parte del debate respecto a la libertad de expresión y la "neutralidad de la red", pero lo cierto es que esta tecnología se basa en códigos que son escritos por hombres, no por máquinas. Lawrence Lessig (1999) explica que las regulaciones dependen de la arquitectura del espacio y esta arquitectura puede ser cambiada: el código del ciberespacio puede inhabilitar las decisiones de gobiernos (su poder de regular comportamientos) o de los individuos, porque define lo que es posible en ese espacio. El poder recae en aquellos que escriben el código. El autor (1998) argumenta que la arquitectura vuelve a internet, desde una perspectiva legal, esencialmente irregulable, dada la facilidad de ocultar quién es quién, pero tiene el potencial de convertirse en el espacio más regulado que se haya conocido.

\section{El imaginario colectivo}

El término imaginario colectivo está directamente relacionado con la capacidad que poseen grupos sociales para crear diversas realidades en determinados momentos históricos, por lo 
que la elaboración del imaginario es una característica distintiva de la vida en sociedad, en tal sentido, es intrínseco su atributo de social o colectivo.

Por su parte, el concepto de imaginario tiene una larga historia debido a que ha sido desarrollado desde diversas disciplinas: desde la antropología, la filosofía, el psicoanálisis y la sociología, principalmente.

El interés por reflexionar sobre el concepto de imaginario social tiene su origen en Francia, cuando Emile Durkheim lo esboza desde una visión más cercana a las representaciones en su afán de explicar por qué es posible el orden social. En tal sentido, analiza las representaciones colectivas en su libro Las formas elementales de la vida religiosa, en el que resalta que las representaciones son parte constitutiva de la realidad social y revela el elemento simbólico de la vida en sociedad. La idea instalada por el sociólogo de la existencia de una conciencia colectiva vinculándola con la explicación de los fenómenos sociales fue un aporte para el desarrollo posterior del concepto "imaginario colectivo".

En el ámbito académico es reiteradamente destacada la contribución que Cornelius Castoriadis realizó al concepto de imaginario social. El imaginario social tal como es concebido por Castoriadis no es la representación de ningún objeto o sujeto, sino la constante creación de los integrantes de las sociedades de formas e imágenes que proveen contenidos significativos y lo entretejen en las estructuras simbólicas de la sociedad.

El sociólogo y filósofo francés, Olivier Fressard (2006), al profundizar el concepto en base al planteo de Castoriadis, es tajante al afirmar que es un "magma de significaciones imaginarias sociales encarnadas en instituciones. Como tal, regula el decir y orienta la acción de los miembros de esa sociedad, en la que determina tanto las maneras de sentir y desear como las maneras de pensar" $(\mathrm{S} / \mathrm{N})$.

Esto es posible, según Fressard (2006, S/N), porque el imaginario social está conformado por fenómenos que trascienden lo individual o la imaginación psicológica, "es obra de un colectivo anónimo e indivisible, que trasciende a los individuos y se impone a ellos. El imaginario social provee a la psique de significaciones y valores, y a los individuos les da los medios para comunicarse y los dota de las formas de la cooperación. Es así, no a la inversa".

Por su parte, Gabriel Ugas Fermín (2007: 49) sostiene que "es la codificación que elaboran las sociedades para nombrar una realidad; en esa medida el imaginario se constituye como elemento de cultura y matriz que ordena y expresa la memoria colectiva, mediada por valoraciones ideológicas, auto-representaciones e imágenes identitarias". 
Esta capacidad que posee una sociedad se diferencia de los atributos individuales de las personas que utilizan la imaginación para recrear e imitar la realidad social a través del conjunto de imágenes que conforman la memoria.

El investigador social José Cegarra (2012) establece la diferencia entre la imaginación y el imaginario al considerar a la primera como representativa y al imaginario como interpretativo. No obstante, la delgada línea que los separa hizo que históricamente distintos autores recurrieran a uno $u$ otro concepto para explicar aspectos similares de la realidad social. Es por ello que resulta conveniente analizar las diferencias entre ambos términos.

El concepto de representaciones sociales propuesto por Serge Moscovici, en 1961, se constituye en un punto de partida ineludible para la elaboración de una definición del término. Este psicólogo social las define como:

Una modalidad particular del conocimiento, cuya función es la elaboración de los comportamientos y la comunicación entre los individuos (...) La representación es un corpus organizado de conocimientos y una de las actividades psíquicas gracias a las cuales los hombres hacen inteligible la realidad física y social, se integran en un grupo o en una relación cotidiana de intercambios, liberan los poderes de su imaginación (Moscovici, 1979: 17 y 18).

Para Moscovici las representaciones sociales son una forma especial de adquirir y comunicar conocimientos, una manera que crea la realidad y el sentido común. Al ser generadas y adquiridas, las representaciones sociales no están preestablecidas sino que son fruto de las interacciones sociales.

Por su parte, la investigadora Denise Jodelet (2000: 10) -ex alumna y colaboradora cercana de Moscovici- ofrece una definición aún más completa:

Las representaciones sociales conciernen al conocimiento del sentido común, que se pone a disposición en la experiencia cotidiana; son sistemas de significaciones que permiten interpretar el curso de los acontecimientos y las relaciones sociales; que expresan la relación que los individuos y los grupos mantienen con el mundo y los otros; que son forjadas en la interacción y el contacto con los discursos que circulan en el espacio público; que están inscriptas en el lenguaje y las prácticas.

Edgar Morin, entiende el imaginario colectivo como un concepto contenido en el de cultura. El sociólogo francés explica a la cultura, en primera instancia, desde una concepción antropológica, entendida como aquello que:

Orienta, desarrolla y domestica ciertas virtualidades humanas y prohíbe u olvida otras. Existen hechos culturales universales, como la prohibición del incesto, pero las reglas y modalidades de esta prohibición se diferencian según las diversas culturas. Dicho de otra forma, hay por una 
parte una 'cultura' que define, en relación a la naturaleza, las cualidades propiamente humanas de ese ser biológico llamado hombre, y por otra parte, culturas particulares según las épocas y las sociedades (Morín, 1966: 21).

Desde esta mirada antropológica el ser humano posee dos cualidades. Una es la razón, que lo diferencia de las otras especies y lo hace único, pero por otra parte, también posee un lado irracional, asociado con los sueños y la imaginación. Es en esta dualidad donde radica lo imaginario y lo real, como capacidades propias del ser, que inciden en los individuos al estructurar sus instintos y orientar sus emociones y que inciden en las prácticas.

Fressard se detiene en la relación conceptual entre imaginario social e institución. Para comprender el alcance y relevancia del imaginario social, el pensador francés asegura que es esencial partir de la idea de que la sociedad es "instituida", lo que significa que no ha sido producida naturalmente, sino como resultado de la acción humana.

Los sistemas sociales se constituyen y afianzan en base a valores, normas, costumbres y una visión del mundo en común que guía a los individuos en tanto integrantes de grupos que constituyen la esencia de toda sociedad. Es en este marco en el que actúan, en determinados momentos históricos, y elaboran y hacen circular ideas cuyo poder simbólico contribuyen a instalar imaginarios que se convierten en tales cuando socialmente son percibidos como "algo natural".

En tal sentido, Pintos (1995: 11) considera que "los imaginarios sociales tienen una función primaria que se podría definir como la elaboración y distribución generalizada de instrumentos de percepción de la realidad social construida como realmente existente".

Hay una coincidencia entre los teóricos en entender a los imaginarios sociales como esquemas de percepción que permiten a los integrantes de una sociedad comprender, explicar e intervenir en determinados fenómenos sociales, o como una matriz de sentido que se impone como interpretación de la vida social, que es históricamente resignificada por los diversos grupos sociales.

Cegarra (2012: 7) rescata las tres premisas propuestas por Jaques LeGoff para entender la importancia simbólica de los imaginarios: 1. los imaginarios sociales tienen una materialidad tangible en los documentos y monumentos erigidos por las sociedades. Por tanto, pueden ser objeto de análisis como evidencia empírica. 2. Los imaginarios sociales son históricamente reconocibles y se constituyen en fuente para la comprensión de los "esquemas interpretativos" de los grupos sociales. 3. El historiador recurre a distintas fuentes como el mito, lo literario, la escultura, arquitectura y otras tantas prácticas sociales humanas que revelan un simbolismo y 
un sentido que puede ser "descifrado" históricamente, dando claves sobre distintos aspectos de la vida cotidiana que bajo otros métodos sería imposible captar.

De estas premisas se puede entender el imaginario como "esquema interpretativo" que hace posible la realidad social al impulsar diversas prácticas sociales, por lo que interviene en la formación y construcción permanente de la compleja trama social. Esto ayudaría a comprender cómo se configuran los imaginarios y sus implicaciones sociales, culturales, educativas 0 políticas.

Baczko (1991: 28) además expone que con los imaginarios la colectividad define su identidad construyendo su propio sistema de referencias. Así el imaginario regula la acción social. La escuela, los medios masivos de comunicación y otras instituciones difunden los imaginarios dominantes a fin de controlar la circulación de determinados símbolos, esquemas interpretativos y discursos legitimadores, propone Baczko (1991: 30).

Es así como en las sociedades modernas lo imaginario está vinculado con la producción de creencias e imágenes colectivas, en la que lo deseable, lo imaginable está estrechamente vinculado con la acción de los medios de comunicación.

En tal sentido, Edgar Morin sostiene que el conjunto de mitos y símbolos que circulan en una sociedad es alimentado, en su dimensión real e imaginaria, por los medios de comunicación.

\section{El imaginario colectivo de internet}

El concepto de imaginario colectivo relacionado a internet está vinculado con creencias y símbolos cargados de significaciones que circulan en la sociedad y que aportan una manera de entender el funcionamiento de esta tecnología, lo que genera que determinados grupos sociales elaboren una percepción particular de internet.

Como ejemplo se puede nombrar la idea etérea de "la nube". Mediante esta construcción simbólica, los integrantes de la sociedad ven a internet como un espacio intangible capaz de almacenar y hacer circular datos e información de manera ilimitada sin la intervención de componentes materiales ni de empresas en la conformación de centros de almacenamiento de datos.

El concepto de imaginario está relacionado con las prácticas de las organizaciones. Por lo tanto, no se puede ignorar que los intereses de sectores del poder elaboran ideas simbólicas que hacen circular hasta convertirlas en un principio configurador del pensamiento social. En ciertos momentos por los que atraviesan las sociedades la comprensión de fenómenos sociales 
está sometida a diversas formas de interpretación, en las que en determinadas circunstancias la razón y el imaginario confluyen o se distancian.

En la sociedad occidental se pueden encontrar ideas que tienden a describir qué es internet, pero no necesariamente esas ideas contienen en sí información clara respecto a los aspectos técnicos sobre el funcionamiento de la red de redes. Aun así, las personas generan una imagen de internet en base a esas ideas, que son difundidas por gobiernos, empresas, medios de comunicación y por el sistema educativo. A su vez, ese esquema que logran formar sobre internet influye en las prácticas cotidianas.

Osenga (2013) cree que las metáforas pueden convertirse en la herramienta primaria que el público general usa para entender las políticas de información respecto a internet, por lo que la autora evalúa el entendimiento de internet a partir de metáforas como "tubos", "autopista", "ciberespacio" y "nube".

Si antes, el imaginario de internet estaba más relacionado a un conducto que llevaba información de un punto a otro, ahora -tomando el concepto de "nube"- se convirtió en un amalgamador donde reside el contenido.

En concordancia con este planteo, Gervais y Hyndman (2012) explican que el término de la nube es utilizado para describir "una infraestructura en la que los usuarios se conectan a dispositivos externos a través de internet pero generalmente no tienen conocimiento de la naturaleza o siquiera de la locación del servidor en el que los datos y el software están localizados" (56).

Por lo tanto, si se toman estos esquemas sobre internet, no aportan información concreta más allá de describir que internet es rápida, infinita, omnipresente e invisible. La posibilidad de acceso a un mismo contenido desde diversos dispositivos, la sincronización de datos o la información editable colectivamente en línea, son algunas de las posibilidades que ha permitido internet en los últimos años. Sin embargo, si estas actividades son realizadas por las personas bajo un esquema de interpretación que se limita a la "nube" (o similares metáforas), no sorprende que no se indague respecto a cómo todas esas actividades son posibles.

La facilidad del uso de los dispositivos electrónicos para la satisfacción de variados tipos de necesidades conlleva una manera específica de percibirlos. En tal sentido internet, como posibilitador y potenciador de las capacidades propias de cada uno de estos artefactos, -si se tiene una conexión paga - está constantemente disponible para el usuario. Aquellos que disfrutan de esta conexión permanente, es posible que interpreten que internet está y estará siempre disponible para seguir satisfaciéndolos. 
Además, las personas perciben internet desde un determinado sistema de referencias, que abunda en símbolos que representan una visión sesgada de internet. Estos símbolos resaltan ciertas características que coinciden poco con la realidad. Al contrario de cómo el imaginario parecería representarlo, internet no sólo es físicamente visible, sino también es limitado en cuanto a la capacidad, distancia, conexión y velocidad.

Las empresas que brindan servicios o productos relacionados a las nuevas tecnologías e internet, muchas veces influyen fuertemente para afianzar esa percepción. Tal como afirma Aparici: "Paralelo a todas las bondades reales que nos proporcionan las nuevas tecnologías, las estrategias de marketing refuerzan con atributos reales y, a veces, mágicos características o cualidades que no poseen" (2000: 20).

Por otro lado, en la conformación del imaginario se ignoran otros aspectos relevantes de internet, como el control, la seguridad y otros temas vinculados con la gobernanza. El sistema simbólico brinda poca información concreta sobre estos factores, lo que contribuye a reforzar la creencia de que internet no tiene dueños y los únicos nombres de empresas que llegan a conocimiento del público general son las de aquellas que brindan el servicio al usuario.

La producción de creencias así como las prácticas en relación a internet, se configuran entonces por el esquema que brinda el imaginario colectivo a través de las instituciones y empresas. Al encarnarse en reducidos sectores de poder, el imaginario de internet es parte de un sistema cultural dominante que propaga determinados valores y costumbres.

Por otra parte, McEvoy (2010) explica la visión de la metáfora "ciberespacio", al afirmar que a partir de 1980 fue redefinido como una extensión del mercado debido al desarrollo del ecommerce. Desde esta visión, internet es un campo que cubre las estructuras de poder tradicionales en ese nuevo territorio. El desarrollo del e-commerce "sugirió que mientras el ciberespacio podría no tener género o nacionalidad, sí tenía una ideología económica. Internet es capitalista, no socialista (...) y por lo tanto, puede ser discutido, el ciberespacio fue también construido como 'occidental', hasta inclusive norteamericano" (2010: 385).

Sin embargo, el imaginario de internet no se puede reducir a simplificaciones, por el contrario, es complejo y cambiante y puede abarcar interpretaciones contrapuestas de diversos grupos sociales. Vayreda (2004: 62) afirma que "el imaginario de las Comunicaciones Mediadas por Ordenador (CMO) no es un tejido de sentidos, liso, sin rupturas ni fisuras. Al contrario, su fuerza radica justamente en su capacidad de acomodar la diversidad, e, incluso, la contradicción". Además explica que esta diversidad es visible en el mismo diseño de los dispositivos, en discursos de sus creadores, en proyectos de comunidades virtuales, en la publicidad, así como en los debates y las publicaciones científicas. 


\section{Qué es internet para los jóvenes universitarios}

La primera etapa del estudio, que consistió en la realización de entrevistas con preguntas abiertas a estudiantes universitarios de primero y segundo año que cursan carreras del área de Ciencias Sociales en establecimientos privados del Área Metropolitana de Buenos Aires (AMBA), permitió obtener una muestra de los conocimientos concretos que los jóvenes con un pequeño recorrido en universidades poseen de internet, de los aspectos que consideran relevantes y de aquellos que no tienen en cuenta.

En base a las respuestas brindadas por 112 jóvenes (mitad hombres y mitad mujeres) surgen las siguientes consideraciones:

Más del 65\% de los entrevistados definieron a internet como un medio masivo de comunicación en el que confluyen además otros medios. En el caso de los hombres es percibido como "el más grande de los medios"; en tanto que las mujeres sostuvieron, además, que es un recurso de información que posee la cualidad de la rapidez, tanto para buscar, transmitir y recibir información, por lo que también es muy valorada la posibilidad de interconexión que brinda esta tecnología. La distinción que en este caso se realiza entre las respuestas dadas por hombres y mujeres se debe a que las estudiantes consultadas expusieron una mayor cantidad de características sobre internet que implica un elevado grado valoración en cuanto a las cualidades de la red de redes, en cambio, los varones se limitaron al uso de un adjetivo para cualificarla.

El segundo aspecto vinculado con la definición de internet es el concepto de red, aunque es expresado de múltiples formas y de manera superficial. La mayoría la define como una red de alcance mundial o global, conformada a su vez por distintas redes interconectadas entre sí. La expresión "conjunto de redes" casi no aparece.

En las respuestas también surgen términos como plataforma, herramienta, soporte y/o tecnología con el agregado de alcance global, que conecta a las personas y sociedades de todo el mundo. Esta idea de interconexión global está presente de manera significativa y es uno de los reiterados atributos que le otorgan.

Aunque la asociación que realizan de este conjunto de redes interconectadas es de toda índole: en muchos casos es percibida como "una plataforma red virtual", en ocasiones se la percibe como una red inalámbrica que no tiene un lugar físico, sino que es descentralizada y libre. 
En un caso se la relacionó con una red de servidores y, sólo una de las entrevistadas elaboró una respuesta más amplia y completa: "Es una red global de comunicación informática que permite la interconexión de manera descentralizada a través de cables de fibra óptica interoceánica, por lo que el acceso no llega a todos los territorios del mundo, sostuvo Karina, de 20 años".

Al momento de definirla también incluyeron atributos o características derivadas del uso, es así que es percibida como una gran fuente de información y base de datos. Algunos fueron más lejos al verla como una gran biblioteca virtual mundial.

Otro dato significativo es la constante utilización de adjetivos asociados a esta tecnología de la comunicación, entre los que se destaca: "gran".

Las entrevistas en profundidad que se realizaron a seis estudiantes de universidades públicas, giraron en torno a cuatro aspectos principales: la definición de internet, la comercialización de datos, la libertad en el uso de internet en relación a la gobernanza y su estructura física.

Es importante destacar que estos encuentros con los estudiantes se realizaron en el entorno social cotidiano de cada uno de los entrevistados, para lograr mayor sinceridad y comodidad en el proceso.

En general, la primera reacción de los participantes frente a las preguntas fue de desconcierto debido a que reconocieron que nunca habían analizado ninguno de estos aspectos de internet; en repetidas ocasiones señalaron: "nunca me lo puse a pensar" o "nunca me lo imaginé". Por lo que no fue sencillo abordar directamente los temas sino que fue necesario utilizar constantes ejemplos para graficar el uso cotidiano de internet. Es por esto que se optó por partir de los aspectos más tangibles a los más intangibles.

Los entrevistados evidenciaron un total desconocimiento de la estructura física de internet; sólo una de las estudiantes participantes hizo referencia a un datacenter de forma tangencial al hablar de una "nube" en donde queda guardada la información que circula en internet que "debe ser como los lugares de las películas que son grandes y están llenos de luces".

Respecto a la forma en la que el servicio llega a los hogares, tres personas indicaron que reciben una "señal" a través de satélites al igual que sucede con el servicio de TV por cable que proveen las empresas del sector. Las respuestas fueron ambiguas debido a que lo relacionaron a su vez con una señal "por satélite" de los celulares pero que no eran las mismas que las de internet. Las únicas empresas nombradas en relación a la estructura de internet fueron aquellas que brindan el servicio a los consumidores (Speedy, Fibertel o Arnet).

El uso de datos personales por parte de las empresas fue ampliamente relacionado a las publicidades que aparecen sobre búsquedas o sitios webs. En este sentido, cuatro de las seis 
personas nombraron empresas como Google, Facebook y Whatsapp, quienes tienen acceso a los datos que los usuarios cargan en sus aplicaciones. Uno de los entrevistados afirmó "haber escuchado en el noticiero" sobre formas para bloquear la información de la ubicación del teléfono móvil en las aplicaciones de Google.

Al indagar respecto a las publicidades personalizadas la relacionaron con "bases de datos" que tienen las empresas o que las webs gratuitas venden espacios de publicidad. Sin embargo, no hubo una respuesta concreta que indicara conocimiento sobre la comercialización ni el uso de los datos que efectúan las empresas. En algunos casos, por desconocimiento del tema, se lo relacionó al mismo tiempo con el robo de datos por parte de hackers.

Además, ninguna de las personas entrevistadas pudo nombrar algún tipo de institución, organismo gubernamental o asociación relacionado con las regulaciones de internet. Frente a preguntas sobre si consideran a internet como un espacio libre en el que se puede encontrar todo tipo de información y hablar de cualquier tema, la mitad de los jóvenes consultados dieron respuestas imprecisas, pero no indicaron una idea de control sobre el contenido publicado o buscado en internet.

Dos personas afirmaron que estaba relacionado a la libertad de expresión de cada país o al acceso a "negocios paralelos" -al intentar hacer una referencia a la deep web-, y una sola entrevistada indicó que no es posible acceder a toda la información. Además expresó que "alguien tiene que manejar toda esa información" y que no estaba segura de que se borraban por completo los contenidos cuando lo hace el usuario.

Por otro lado, ninguno de los jóvenes universitarios hizo referencia acerca del debate internacional que se está dando en los últimos tiempos sobre la gobernanza de internet.

Por otra parte, ante la pregunta qué es internet, la mayoría de las definiciones brindadas destacaron su aspecto comunicacional: "herramienta de comunicación", "forma de comunicación", "señales que se mandan y le llegan a otras personas". También hubo una definición que se destacó del resto aunque dentro del marco de las vaguedades características de estas entrevistas: "es un medio basado en códigos controlados por distintas personas".

\section{Conclusiones}

Internet, entendida como una tecnología de comunicación que permite la interacción a gran escala, se sustenta en un entramado tecnológico complejo. Sin embargo, las características que permiten su funcionamiento no son motivo de interés para los usuarios. 
Internet es percibida -principalmente por los jóvenes- desde un punto de vista sesgado, al no considerarla desde los aspectos técnicos, legales, de seguridad, ni otros relacionados con la gobernanza. Por el contrario, hay un marcado desconocimiento entre las personas no especializadas sobre lo que es internet y cuál es su funcionamiento. Esta percepción está conformada por un imaginario colectivo de esta tecnología que muchas veces no coincide con la realidad. En tal sentido, en este trabajo se pudo identificar un conocimiento limitado en 118 jóvenes universitarios del Área Metropolitana de Buenos Aires respecto a los aspectos de internet que van más allá del contenido digital o de las relaciones de interconexión grupal, dimensiones que provienen solamente de las prácticas de uso cotidiano de la tecnología.

Los grupos de jóvenes nativos digitales entrevistados que cursan en los primeros años de la universidad brindaron información concreta respecto a su estado de conocimiento sobre qué es internet y cuáles son sus atributos principales:

-La mayoría la consideró un medio masivo de comunicación. Otras respuestas concordantes con esa percepción la definieron como herramienta de comunicación, forma de comunicación o recurso de información.

-Apareció el concepto de red pero no como conjunto de redes.

-En numerosos casos se la ve como a una gran fuente de información y prevaleció el uso de la metáfora biblioteca virtual.

- Las cualidades destacadas son la rapidez e interconexión global.

-Sólo una persona hizo mención a la estructura física de internet pero varios nombraron la palabra "nube" en relación al almacenamiento de información.

Las entrevistas en profundidad arrojaron además datos sobre otros aspectos de internet:

-La posibilidad de que las empresas tengan bases de datos personales de los usuarios fue mencionada pero desconocen de dónde los podrían obtener.

-Las únicas empresas relacionadas a internet mencionadas son aquellas que brindan el servicio a usuarios en Buenos Aires y las aplicaciones digitales (Facebook, Whatsapp, Instagram).

-No fueron mencionadas instituciones, organismos gubernamentales 0 asociaciones relacionadas con las regulaciones de internet.

-La totalidad de los entrevistados aseguraron "nunca haber realmente pensado sobre el tema".

Los resultados derivados de las herramientas metodológicas utilizadas permiten esbozar una primera conclusión: la percepción que los jóvenes digitalizados de AMBA tienen sobre internet 
se sustenta principalmente en las imágenes, mitos y símbolos que se construyen en torno a esta tecnología más que en información precisa.

Lo expresado anteriormente sugiere que el imaginario colectivo sobre internet está formado por un conjunto de símbolos elaborados como metáforas: "autopista de información"," ciberespacio" y "nube". La idea de "nube", por ejemplo, se utiliza para representar un conjunto de servidores en los que se almacenan, fuera de sus dispositivos, los datos generados por los usuarios, que en su mayoría desconocen su localización.

De esta forma, si internet es percibida a partir de este sistema de símbolos y el conocimiento sobre esta tecnología se sustenta principalmente en el uso diario de dispositivos potenciados por la tecnología de internet, se desplazan en la mente colectiva otros aspectos que la caracterizan y la definen.

En tal sentido, el grupo que fue objeto de estudio de esta investigación alimenta una percepción que se vincula con la omnipresencia de internet, idea que desplaza toda relación con la estructura material de la red de redes, con las empresas que son dueñas de esa estructura y de instituciones, organizaciones de la sociedad civil y gobiernos que se encargan de establecer las normativas de funcionamiento y del control de su seguridad.

El imaginario parece estar además incluyendo otras características que no tienen un sustento real, como lo es la invisibilidad de internet.

Aunque sea utópico pretender que todos los individuos tengan un conocimiento profundo de los conceptos de cada tecnología que se usa a diario, resulta interesante destacar que el imaginario colectivo resalte ciertas características específicas de internet relacionadas con el uso de esta tecnología y no se repare en sus implicancias ni consecuencias, lo que desplaza toda interrogación sobre el funcionamiento y las regulaciones de la red de redes.

Este tema debe ser abordado más exhaustivamente en próximos análisis, principalmente respecto a los factores que inciden en la construcción de ese imaginario particular, como el papel de las instituciones, tanto del ámbito público como del privado, en la creación del imaginario colectivo.

Si bien no es el objetivo aquí propuesto indagar sobre estos aspectos, la cultura dominante impone imaginarios $\mathrm{y}$, por lo tanto, no se puede ignorar que el sistema educativo formal, el sector empresarial e industrial y los medios de comunicación influyen en la creación de una idea colectiva sobre internet.

Además quedan abiertas posibles preguntas con relación a los intereses económicos y políticos en la construcción del imaginario colectivo sobre internet. En este sentido el imaginario de la tecnología no estaría ajeno y libre de esos intereses, como tampoco lo está internet en el 
plano de la realidad tangible. Su diseño es creado, modificado y regulado por diversos sectores de poder, y su estructura física tiene dueños privados concretos.

Por último, tal vez resulte pertinente plantear una serie de interrogantes, derivados de este trabajo, que se puedan responder en sucesivos estudios: ¿Por qué las instituciones moldean un imaginario colectivo sesgado sobre internet? ¿A quiénes podría beneficiar la desinformación respecto a una tecnología usada por gran parte de la población occidental?

\section{Bibliografía}

Aparici, M. (2000). Trece mitos sobre las nuevas tecnologías de la información y de la comunicación. Tabanque: Revista pedagógica, 14, Universidad de Valladolid, pp. 1926.

Baczko, B. (1991). Los imaginarios sociales. Memorias y esperanzas colectivas. Buenos Aires: Nueva Visión.

Castells, M. (1999). Internet y la Sociedad Red. Lección inaugural del programa de doctorado sobre la sociedad de la información y el conocimiento (UOC), Universitat Oberta de Catalunya. Recuperado de http://www.uoc.edu/web/cat/articles/castells/castellsmain2.html.

Castells, M. (2008). Comunicación, poder y contrapoder en la sociedad red. Los medios y la política. Revista Telos, 74, Fundación Telefónica, Madrid.

Cegarra, J. (2012). Fundamentos Teórico Epistemológicos de los Imaginarios Sociales. Cinta de Moebío: Revista de Epistemología de Ciencias Sociales, 43, Facultad de Ciencias Sociales, Universidad de Chile, pp. 1-13.

Fressard, O. (2006). El imaginario social o la potencia de inventar los pueblos. Revista Transversales, II(2), Asociación Transversales y Editorial Sepha, España. Recuperado de http://www.trasversales.net/t02olfre.htm

Gervais D. y Hyndman, D. (2012). Cloud Control: Copyright, Global Memes and Privacy. Journal on Telecommunications and High Technology Law. Working Paper Number 1210. Vanderbilt University Law School.

Jodelet, D. (2000). Representaciones sociales: contribución a un saber sociocultural sin fronteras. En Jodelet, D. y Guerrero Tapia, A. (Coord). Develando la cultura. Estudios en representaciones sociales. Universidad Nacional Autónoma de México: México D.F. 
Krol, E. (1992). The Whole Internet User's Guide and Catalog. Estados Unidos: Ed: O'Reilly Media.

McEvoy Manjikian, M. (2010). From Global Village to Virtual Battlespace: The Colonizing of the Internet and the Extension of Realpolitik. International Studies Quarterly, 54(2), pp. 381401.

Lessig, L. (1999). Code and Other Laws of Cyberspace. New York: Ed: Basic Books. Morin, E. (1966). El espíritu del tiempo. Madrid: Ed. Taurus.

Morris, M. (1996). The Internet as a mass médium. Journal of Computer-mediated communication. 1(issue 4). Recuperado de https://academic.oup.com/joc/articleabstract/46/1/39/4160238?redirectedFrom=fulltext

Moscovici, S. (1979). El psicoanálisis, su imagen y su público. Buenos Aires: Editorial Huemul.

Osenga, K. (2013). The Internet is Not a Super Highway: Using Metaphors to Communicate Information and Communications. Journal of Information Policy, 3, pp. 30-54. Penn State University Press.

Pavlou, P.; Anderson, A.; Huigang, L. y Yaijong, X. (2007). Understanding and Mitigat- ing Uncertainty in Online Exchange Relationships: A Principal-Agent Perspective. MIS Quarterly. International Studies Quarterly, 54(2), pp. 381-401.

Pintos, J. (1995). Los imaginarios sociales. La nueva construcción de la realidad social. Madrid: Editorial Sal Terrae/Fe y Secularidad.

Ugas Fermin, G. (2007). La educada ignorancia: Un modo de ser del pensamiento. Revista de Epistemología de Ciencias Sociales, Facultad de Ciencias Sociales, Universidad de Chile, 43, pp. 1-13.

Vayreda, A. (2004). Las promesas del imaginario internet: las comunidades virtuales. Athenea Digital, 5, Universitat Oberta de Catalunya, pp. 57-78. Zuazo, N. (2013). Guerras de internet. Buenos Aires: Ed: Debate.

Zukerfeld, M. (2010). De niveles, regulaciones capitalistas y cables submarinos. Revista Virtualis, 1, Tecnológico de Monterrey. 